\title{
Regulated Emissions and Detailed Particle Characterisation for Diesel and RME Biodiesel Fuel Combustion with Varying EGR in a Heavy-Duty Engine
}

Novakovic, Maja; Shamun, Sam; Malmborg, Vilhelm B.; Kling, Kirsten I.; Kling, Jens; Vogel, Ulla B.; Tunestal, Per; Pagels, Joakim; Tuner, Martin

Published in:

2019 JSAE/SAE Powertrains, Fuels and Lubricants International Meeting

Link to article, DOI:

$10.4271 / 2019-01-2291$

Publication date:

2019

Document Version

Peer reviewed version

Link back to DTU Orbit

Citation (APA):

Novakovic, M., Shamun, S., Malmborg, V. B., Kling, K. I., Kling, J., Vogel, U. B., Tunestal, P., Pagels, J., \& Tuner, M. (2019). Regulated Emissions and Detailed Particle Characterisation for Diesel and RME Biodiesel Fuel Combustion with Varying EGR in a Heavy-Duty Engine. In 2019 JSAE/SAE Powertrains, Fuels and Lubricants International Meeting (December ed., Vol. 2019). Society of Automotive Engineers. SAE Technical Papers https://doi.org/10.4271/2019-01-2291

\section{General rights}

Copyright and moral rights for the publications made accessible in the public portal are retained by the authors and/or other copyright owners and it is a condition of accessing publications that users recognise and abide by the legal requirements associated with these rights.

- Users may download and print one copy of any publication from the public portal for the purpose of private study or research.

- You may not further distribute the material or use it for any profit-making activity or commercial gain

- You may freely distribute the URL identifying the publication in the public portal 


\title{
Optimization of Truss Girders in Cable-Supported Bridges Including Stability
}

\author{
Mads Baandrup ${ }^{1}$; Peter Noe Poulsen²; John Forbes Olesen ${ }^{3}$; and Henrik Polk ${ }^{4}$
}

\begin{abstract}
The main design principles for girders in cable-supported bridges have not changed significantly over the past 60 years, and are limited in further development. The design concept suffers from substantial fatigue issues, and will be challenged by self-weight in future very-long bridges with main spans beyond $2 \mathrm{~km}$. In this work, truss topology optimization, including global and local stability, is applied in a conceptual study of new weight-reduced designs for girders in cable-supported bridges. The methods are based on finite-element limit analysis and convex optimization. A single section of a continuous girder, subject to local and global loads, is optimized to minimize weight while fulfilling constraints on stresses as well as global and local stability. The optimized designs, significantly different in layout from the conventional, show initial weight savings of up to $45 \%$ compared with the present design. Further parameter studies indicate potential weight savings of up to 54\%. DOI: 10.1061/(ASCE)BE.1943-5592.0001632. C 2020 American Society of Civil Engineers.
\end{abstract}

\section{Introduction}

In the past 60 years, the overall structural system for girders in cable-supported bridges have remained nearly unchanged (Gimsing and Georgakis 2012). The design principles of closed steel box girders with orthotropic decks and transverse diaphragms have been applied in the majority of large suspension bridges since the 1950s (Wolchuk and Harris 1959; Wolchuk 1999). However, the design principles are limited in further development and suffer from substantial fatigue issues (Fisher and Dexter 1997; Kozy and Connor 2010; Zhang 2017). Fatigue issues are inherent in the design, since loads are carried in one direction at a time, leading to stress concentrations at connections (Song and Ding 2014). Furthermore, the design concept will be challenged in the future by its weight, since self-weight is crucial for very-long suspension bridges with main spans beyond $2 \mathrm{~km}$ (Gimsing and Georgakis 2012).

Through the years, the conventional design principles have been subject to several studies and improvements, especially with a focus on reducing fatigue issues. Parametric studies have been carried out experimentally (Aygül et al. 2012; Oh and Bae 2013), analytically (Backer et al. 2006), and numerically, with a focus on cutout details in diaphragms (Connor 2004; Corte 2009; Oh et al. 2011) and the top deck (Fettahoglu 2016). Recently, a new approach to improve the design by gradient-based parametric optimization with the focus on weight minimization has been proposed by Baandrup et al. (2019). In this study, weight savings of $6 \%$ were

\footnotetext{
${ }^{1}$ Dept. of Civil Engineering, Technical Univ. of Denmark, Kgs. Lyngby 2800, Denmark; Dept. of Major Bridges International, COWI A/S, Parallelvej 2, Kgs. Lyngby 2800, Denmark (corresponding author). ORCID: https://orcid.org/0000-0001-6353-7313. Email: mjba@byg.dtu.dk

${ }^{2}$ Dept. of Civil Engineering, Technical Univ. of Denmark, Kgs. Lyngby 2800, Denmark.

${ }^{3}$ Dept. of Civil Engineering, Technical Univ. of Denmark, Kgs. Lyngby 2800, Denmark. ORCID: https://orcid.org/0000-0001-6695-7719.

${ }^{4}$ Dept. of Major Bridges International, COWI A/S, Parallelvej 2, Kgs. Lyngby 2800, Denmark.

Note. This manuscript was submitted on November 21, 2019; approved on June 11, 2020; published online on September 15, 2020. Discussion period open until February 15, 2021; separate discussions must be submitted for individual papers. This paper is part of the Journal of Bridge Engineering, (C) ASCE, ISSN 1084-0702.
}

achieved for current design practice indicating very little room for improvement without altering the concept. Despite the many studies, the overall structural system has not changed significantly. No major changes have been introduced to overcome fatigue issues or reduce weight, and thereby increase the potential span length. However, in future designs of suspension bridges with main spans beyond $2 \mathrm{~km}$, it is anticipated that greater and more radical design changes will be required. In this regard, the weight minimization of the girder is a natural starting point, because the reduced girder weight will have knock-on effects on the supporting bridge components such as cables, towers, and anchor blocks.

In the present paper, an optimization method based on truss structures is utilized as the design tool to identify new conceptual design approaches for girders in cable-supported bridges. The structural layout of a simplified bridge girder model is optimized to reduce weight by the use of truss optimization including global and local stability as well as stress constraints.

The girder model subject to optimization is a single section $\left(25 \times 30.1 \times 4.75 \mathrm{~m}^{3}\right)$ of the continuous girder in a suspension bridge. Outer geometry, dimensions, and load cases are based on the recently constructed Osman Gazi Bridge, which opened to traffic in July 2016. The basis of the conceptual study is an assumption of a fixed top plate spanning up to $3 \mathrm{~m}$ in two directions and, thus, distributing the surface loads to an underlying truss structure. The top plate may be constructed as a sandwich element with steel plate skins (see, e.g., Battista et al. 2010; Corte 2011; Chu et al. 2018). However, in the present work, the focus is on the optimization of the supporting truss structure. The model is subject to both local and global load cases, identified from a global beam model of the Osman Gazi Bridge.

The applied optimization method is based on finite-element limit analysis (FELA) and convex optimization. FELA is based on the finite-element (FE) concept and defines a convex linear optimization problem assuming perfect plastic material behavior. The basis of the methods used in the present paper was introduced in Poulsen et al. (2020) and developed to handle large-scale structures in Baandrup et al. (2020), where methods to reduce truss complexity were formulated. These methods are briefly summarized for completeness and ease of understanding.

Subsequently, the basic methods are extended to handle the bridge girder model with novel constraints imposing the assumed top plate, symmetry conditions, and global section forces. Finally, 
the full problem formulation is applied to the conceptual bridge girder study. The focus of the study is mainly on potential weight reduction and the identification of the overall structural concept. Hence, construction costs and structural details are not considered.

The constraints defining the girder model are validated on a simple model, followed by the optimization of the bridge girder subject to two simple load cases. Subsequently, the complete model is optimized to identify new conceptual designs and possible weight savings. Finally, two parametric studies are carried out to study the effect of varying top plate strength and domain height, respectively.

\section{Methods}

In the following sections, the bridge girder model to be optimized is presented. Here, the geometry, load cases, and boundary conditions of the FE model are introduced together with other assumptions. Subsequently, the main principles of FELA-based truss layout optimization are summarized from Poulsen et al. (2020). Finally, the implementation, combining the bridge girder model with the FELA optimization framework, is described.

\section{Bridge Girder Model}

The conceptual optimization study is based on the recently finalized Osman Gazi Bridge, Turkey, which opened to traffic in July 2016 with a main span of $1,550 \mathrm{~m}$. The bridge design, made by COWI A/S, was state of the art and is considered a suitable reference for the development of a new bridge girder design. The main dimensions and layout are shown in Fig. 1.The girder design is a closed steel box-girder with an orthotropic deck and truss diaphragms every $5 \mathrm{~m}$, see Fig. 2. In the remainder of this paper, this design is designated the conventional design concept.

As the bridge girder is a continuous structure, only one section ( $L=25 \mathrm{~m}$ equivalent to the distance between two sets of hangers) is modeled. The width of the girder is $W=30.1 \mathrm{~m}$ and the height is $H=4.75 \mathrm{~m}$. The domain and outer dimensions are shown in Fig. 3.The outer geometry of the domain is defined by the outer shape of the original design (without walkway), which is the reason for the inclined edges. The aerodynamic shape of the profile is maintained, because aerodynamic issues are outside the scope of the present study.

The section is part of a continuous girder and the loads applied are in equilibrium. The kinematic boundary conditions, imposed on the six degrees of freedom shown in Fig. 3, are applied to prevent any rigid body motion.

The section is modeled with a top plate and a supporting structure of truss elements. It is assumed that a top plate, necessary to carry the traffic loads, is at hand (e.g., some sandwich structure with steel skins Battista et al. 2010; Corte 2011; Chu et al. 2018), spanning up to $3 \mathrm{~m}$ in two directions, distributing the surface loads to the nearest nodes in the underlying truss. The specific design of this top plate is not considered and left for future work. However, in the present work, an equivalent steel plate thickness of $t_{t p}=20 \mathrm{~mm}$ was selected. In the Osman Gazi Bridge, the equivalent plate thickness was $26 \mathrm{~mm}$ for the orthotropic deck (top plate and troughs) spanning $5 \mathrm{~m}$. In the present model, the top plate is

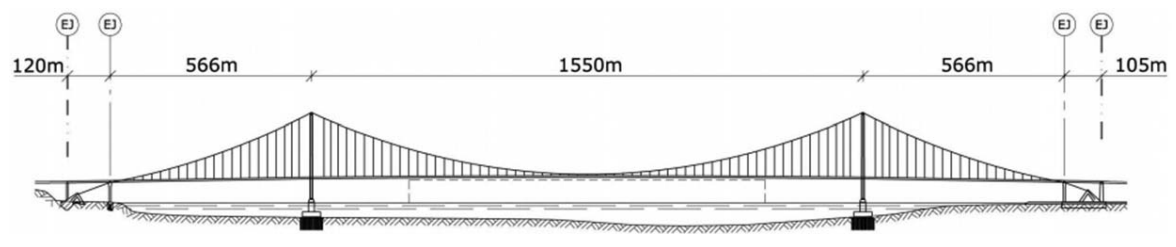

Fig. 1. Main dimensions and layout of the Osman Gazi Bridge (COWI A/S). (Data from Diana et al. 2013.)

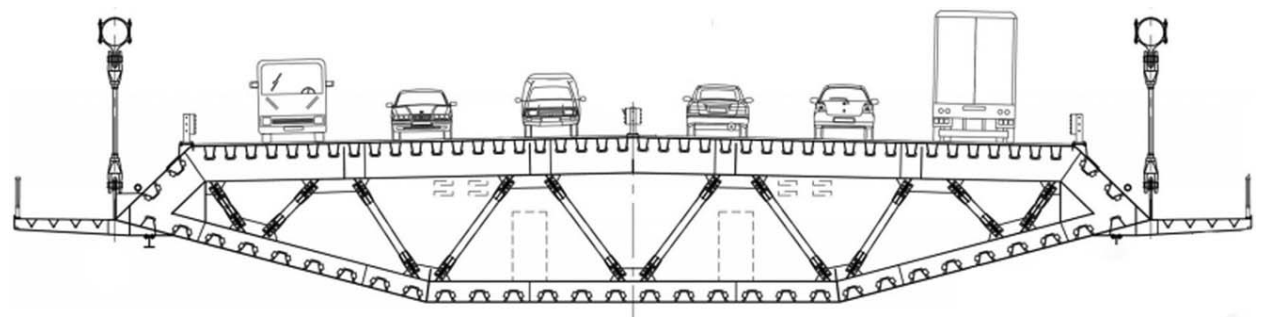

Fig. 2. Design principle of the closed box girder with orthotropic deck and truss diaphragms in the Osman Gazi Bridge (COWI A/S). (Data from Diana et al. 2013.)

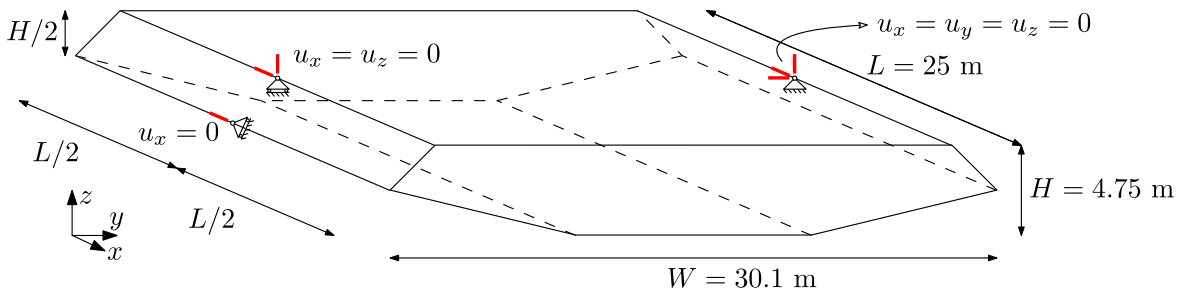

Fig. 3. Domain of one girder section with the indication of dimensions and boundary conditions. 
modeled as a fixed truss grid in the upper layer, as indicated in Fig. 4. As this top truss is fixed, it is only the underlying structure which is optimized.

Furthermore, since the bridge girder is a symmetric and repetitive structure, symmetry constraints are applied. Symmetry lines are given along the longitudinal center line and in the transverse center line of each section, as shown in Fig. 5. This utilization of symmetry significantly reduces the number of unknowns allowing for the modeling of larger systems within given computational limits.

The model is subject to 14 load cases, 12 designated global and two designated local. The applied loads are indicated in Fig. 6 and listed in Table 3 in Appendix I.

The 12 global load cases, LC 1-12, consist of section forces from a global beam model of the bridge. The beam model was developed during the design stage, with the COWI A/S in-house FE software IBDAS (Integrated Bridge Design and Analysis Software). The model, loads (permanent, traffic, wind, seismic action, and temperature), and load combinations were all based on the Eurocode

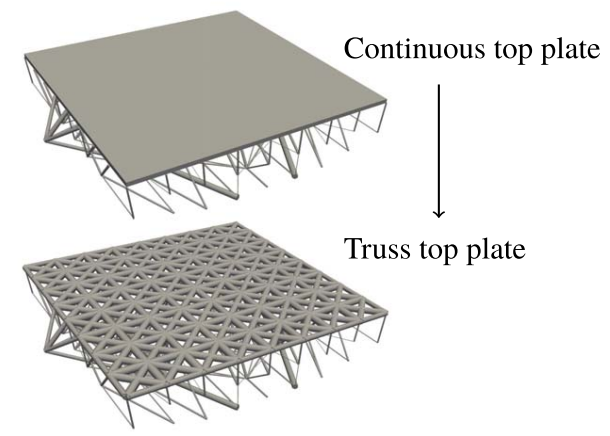

Fig. 4. Assumption of a continuous top plate and equivalent modeled truss top plate.

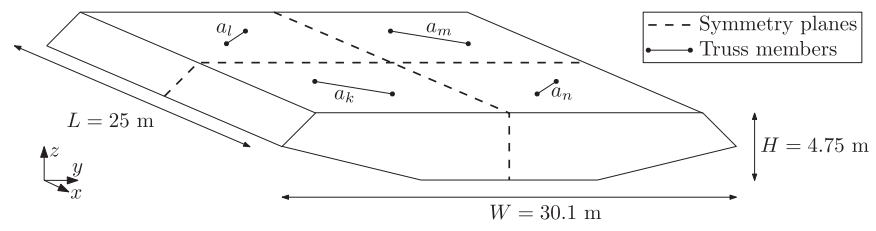

Fig. 5. Symmetry mapping of the structure indicated by truss members with equal area $a_{k}=a_{l}=a_{m}=a_{n}$.

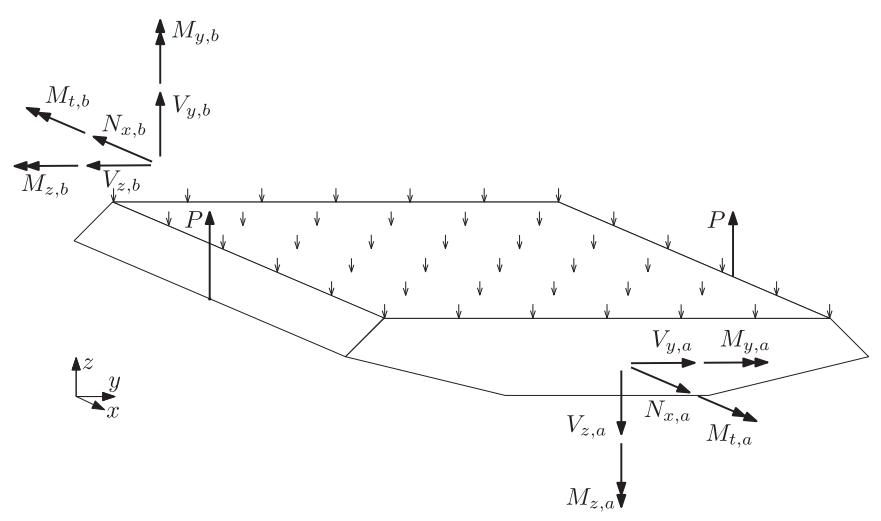

Fig. 6. Global section forces applied to end surfaces, local distributed load $p$ (indicated by downward arrows), and hanger forces $P$.
(CEN 2002, 2003) and the UK National Annexes. From the IBDAS beam model, the most critical (static) section forces in typical sections of the girder were identified. In total 12 sets of critical section forces have been identified, equivalent to the maximum and minimum of the six section forces in a beam $\left(N_{x}, M_{y}, M_{z}, V_{y}, V_{z}, M_{t}\right)$. Each set of forces consists of the global section forces acting on each end surface (End $a$ and $b$ ) of the local model, as indicated in Fig. 6. The set of section forces is applied together with the distributed load $p$ on the top surface and hanger forces $P$ to ensure equilibrium of all loads applied. The section forces in the girder and locally distributed load and hanger forces are given by the beam model.

The two local load cases, LC 13 and 14, consist of a downward uniformly distributed load $p=5 \mathrm{kN} / \mathrm{m}^{2}$ with equivalent upward hanger forces $P$ to ensure equilibrium. In addition, two moments, $M_{y, a}$ and $M_{y, b}$, are applied to the end surfaces to imitate the behavior of the continuous girder. In LC 13 the distributed load is applied to the entire top surface, whereas in LC 14 the load is applied only on one side of the longitudinal center line, to give a skew distribution.

\section{Truss Layout Optimization Including Global and Local Stability}

The bridge girder model is optimized with FELA-based truss layout optimization. The main principles of the applied method were introduced in Poulsen et al. (2020) and are summarized below.

FELA is a numerical method that combines the discretization of a model, known from conventional finite-element analysis (FEA), with limit analysis of structures where rigid-plastic material behavior is assumed as well as small displacements. Normally, displacements are the variables in FEA, whereas the variables in the lower-bound method of FELA are the stresses.

The truss optimization takes the ground-structure approach, and the objective of the optimization is to minimize the total volume (weight) of the truss structure while fulfilling given constraints. The topological design variables are the cross-sectional areas of all members except those in the top plate.

During the optimization, four different constraints must be fulfilled. First, a constraint ensuring equilibrium of nodal forces for all unsupported nodes, in order to establish an admissible stress field. Second, a constraint ensuring that all member stresses are within the yield stress limits. Finally, two different constraints ensuring compliance with restrictions against local and global instability, respectively.

The truss layout optimization problem with the four constraints, as formulated in Poulsen et al. (2020), is given as the convex problem

$$
\begin{gathered}
\min _{\boldsymbol{\beta}, \mathbf{A}} \quad V=\sum_{e=1}^{N_{e}} a_{e} \ell_{e}=\mathbf{A}^{\top} \mathbf{L} \\
\text { s.t. } \quad \mathbf{H} \boldsymbol{\beta}=\mathbf{R} \\
\mathbf{C} \boldsymbol{\beta}-\mathbf{C}_{m} \mathbf{A} \leq \mathbf{0} \\
-\mathbf{I} \boldsymbol{\beta}-\mathbf{P A} \leq \mathbf{q} \\
\mathbf{K}_{G}\left(\boldsymbol{\beta}_{k}\right)+\mathbf{K}(\mathbf{A}) \succeq 0 \quad \forall k=1, \ldots, N_{k}
\end{gathered}
$$

where $e$ refers to the $N_{e}$ individual members and $k$ refers to the $N_{k}$ individual load cases. The main design variables are the member areas collected in $\mathbf{A}$ and the secondary design variables are the bar forces collected in $\boldsymbol{\beta}$. The objective function in $(1 a)$, defining the total truss volume $V$, is given as the summation of the products 
of individual member areas $a_{e}$ and lengths $\ell_{e}$ (collected in vector L). The first constraint $(1 b)$ defines the equilibrium equations, where the equilibrium matrix $\mathbf{H}$ ensures the nodal equilibrium of internal $(\boldsymbol{\beta})$ and external $(\mathbf{R})$ nodal forces for all unsupported nodes. The second constraint (1c) defines the yield condition, or stress constraint. The effect of the constraint may be seen as a conversion of the bar forces to their absolute values $(\mathbf{C})$, which are restricted by the yield stress $f_{y}$, of each bar $\left(\mathbf{C}_{m}\right)$.

The third constraint $(1 d)$ defines the restriction against local instability of each element. The constraint is based on the Euler buckling load $P_{c r}$ for a simply supported member. Hence, the constraint for element $e$ is given as

$$
-\beta_{e} \leq P_{c r, e}=\frac{\pi^{2} \cdot E I_{e}}{\ell_{e}^{2}} \approx \alpha_{e} a_{e}^{2}
$$

where $E$ is the modulus of elasticity and $I_{e}$ the second moment of area. The rightmost quadratic term is exact for a circular crosssection, for other cross-sectional geometries the expression is an approximation (see Poulsen et al. 2020). However, the constraint is non-convex, and it cannot be integrated immediately into the convex optimization problem. To eliminate the non-convex properties of (2), the quadratic constraint is linearized by either its tangent or its secant. The linearizations of (2) for all elements and load cases are assembled to give the matrix expression $(1 d)$, where $\mathbf{I}$ is the identity matrix, $\mathbf{P}$ is a matrix representing the parts of the linearization which are proportional to $a_{e}$, and $\mathbf{q}$ is a vector containing the constant parts.

The final constraint $(1 e)$ defines the restriction against global instability for each of the $N_{k}$ load cases. The constraint is defined as a semidefinite constraint on the linearized buckling stiffness matrix composed of the sum of the global geometric stiffness matrix $\mathbf{K}_{G}$, which is a function of the bar forces, and the global elastic stiffness matrix $\mathbf{K}$, which is a function of the bar areas.

In Baandrup et al. (2020) the optimization problem (1) was reformulated to handle large-scale models. The primal formulation (1) was rewritten to its dual formulation, resulting in a large reduction in computational time and memory demand. This technique is applied here too, however, only the primal formulations are shown in the following.

In this conceptual study, emphasis is on practical solutions, and in particular on lowering construction cost, therefore it is desirable to reduce the truss complexity by reducing the number of members and the number of connections (nodes). In Baandrup et al. (2020), two heuristic methods were formulated to penalize short members and members with small cross-sectional areas. The methods are also applied here to reduce structural complexity.

\section{Arranging the Bridge Girder Model for Truss Optimization}

The implementation of the fixed top plate, the symmetry constraints, and the global section forces into the basic optimization problem (1) is described in the following. Finally, the complete optimization problem is stated.

\section{Fixed Top Plate}

The assumed fixed top plate with a total steel thickness $t_{t p}$ is modeled as a plane grid with truss members, cf. Figs. 4 and 7 . These truss members are assigned fixed cross-sectional areas, such that the strength of the truss top plate is equivalent to the assumed top plate. Furthermore, the area of the members in the top plate (top layer of the truss mesh) are discarded as design variables.

A part of the plate with dimensions $a \times b$, as indicated in Fig. 7, is studied in order to identify the truss cross-sectional areas $a_{x}, a_{y}$, and $a_{x y}$ that ensure a strength equivalent to the strength of a solid

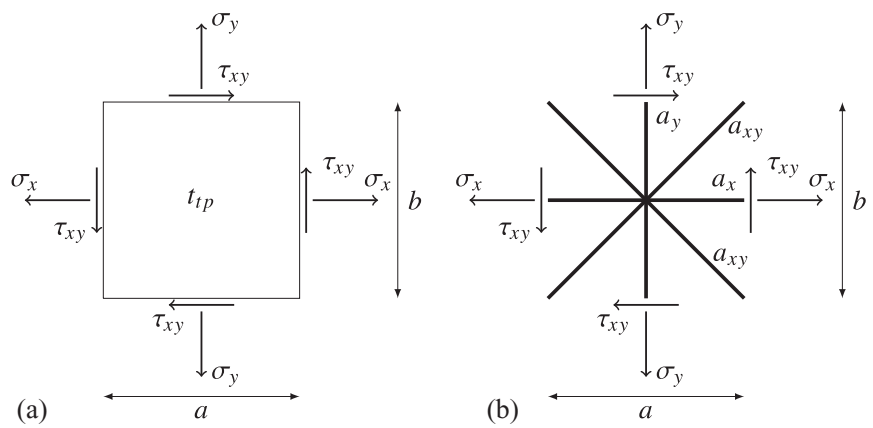

Fig. 7. Structural layout and capacities $\sigma_{x}, \sigma_{y}$, and $\tau_{x y}$ on two types of top plate: (a) plate structures; and (b) truss structure with representative grid elements.

plate.The plate and truss structures in Figs. 7(a and b) should have the same uniaxial capacities $\sigma_{x}$ and $\sigma_{y}$, and shear capacity $\tau_{x y}$. By demanding force equilibrium between the plate and truss structures, the cross-sectional areas are identified as

$$
\begin{gathered}
a_{x}=t_{t p}(b-\beta a) \\
a_{y}=t_{t p}(a-\beta b) \\
a_{x y}=t_{t p} \frac{\beta}{2} \sqrt{a^{2}+b^{2}}
\end{gathered}
$$

where a geometric factor is introduced as $\beta=\frac{1}{2 \sqrt{3}}\left((a+b)^{2} /\right.$ $\left.\left(a^{2}+b^{2}\right)\right)$ in order to fulfill the von Mises yield criterion. The fixed areas are assigned to the top members in the linear equality constraint

$$
\mathbf{D A}=\mathbf{A}_{0}
$$

where $\mathbf{A}_{0}$ contains the fixed areas $a_{x}, a_{y}$, and $a_{x y}$, and $\mathbf{D}$ is an index matrix linking the design variables to the fixed areas. For truss members positioned along the edge of the domain, only half the area is assigned.

\section{Mapping of Symmetry Constraints}

The symmetry mapping (Fig. 5) is implemented with the following linear equality constraint

$$
\mathbf{S A}=\mathbf{0}
$$

where $\mathbf{S}$ is an index matrix mapping the symmetry between the regions $k, l, m$, and $n$. The member areas in each region, represented by $a_{k}, a_{l}, a_{m}$, and $a_{n}$ in Fig. 5, are mirrored, hence $a_{l}=a_{k}, a_{m}=a_{k}$, and $a_{n}=a_{k}$, which can be written as

$$
\mathbf{s}_{k} \mathbf{A}=\left[\begin{array}{ccccccccc}
\cdots & -1 & \cdots & 1 & \cdots & 0 & \cdots & 0 & \cdots \\
\cdots & -1 & \cdots & 0 & \cdots & 1 & \cdots & 0 & \cdots \\
\cdots & -1 & \cdots & 0 & \cdots & 0 & \cdots & 1 & \cdots
\end{array}\right]\left[\begin{array}{c} 
\\
\vdots \\
a_{k} \\
\vdots \\
a_{l} \\
\vdots \\
a_{m} \\
\vdots \\
a_{n} \\
\vdots
\end{array}\right]=\mathbf{0}
$$


where $\mathbf{s}_{k}$ is the mapping matrix for a single element in region $k$, which is added to $\mathbf{S}$.

\section{Global Section Forces}

In contrast to the distributed load $p$ and the hanger forces $P$, which are applied through the $\mathbf{R}$ vector, the global section forces are not applied to specific nodes on the end surfaces. This is not possible, because the distribution of material from the optimization is unknown. Instead, section forces are defined as a summation of nodal forces on the end surfaces, hence the distribution is unrestricted and given as a result of the optimization. The generic summation of each of the six section forces for one end surface with $N_{\text {end }}$ nodes is shown below

$$
\begin{gathered}
N_{x}=\sum_{i=1}^{N_{\text {end }}} F_{x, i} \\
M_{y}=\sum_{i=1}^{N_{\text {end }}} F_{x, i} \cdot z_{i} \\
M_{z}=\sum_{i=1}^{N_{\text {end }}}-F_{x, i} \cdot y_{i} \\
V_{y}=\sum_{i=1}^{N_{\text {end }}} F_{y, i} \\
V_{z}=\sum_{i=1}^{N_{\text {end }}} F_{z, i}
\end{gathered}
$$

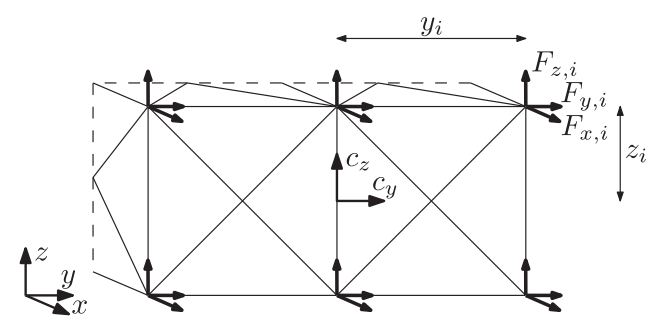

Fig. 8. Contribution of node forces $F$ from node $i$ to the global section forces, with distance $\left(y_{i}, z_{i}\right)$ to the center of the end surface $\left(c_{y}, c_{z}\right)$.

$$
M_{t}=\sum_{i=1}^{N_{\mathrm{end}}}-F_{y, i} \cdot z_{i}+\sum_{i=1}^{N_{\mathrm{end}}} F_{z, i} \cdot y_{i}
$$

where $F_{x, i}, F_{y, i}$, and $F_{z, i}$ are the three nodal forces in node $i$, and $y_{i}$ and $z_{i}$ are the distances to the end surface center $\left(c_{y}, c_{z}\right)$ as indicated in Fig. 8. The nodal forces are found as the sum of components of the bars contributing to node $i$. The sums in (7) are linear functions of the design variables in $\boldsymbol{\beta}$ and the equations can be given as the linear equality constraint

$$
\mathbf{G} \boldsymbol{\beta}=\mathbf{G}_{0}
$$

where $\mathbf{G}$ is a section force equilibrium matrix and $\mathbf{G}_{0}$ is a vector containing the section force values. The vector for the global load case $g$ is given as

$$
\mathbf{G}_{0, g}=\left[N_{x, a, g} M_{y, a, g} M_{z, a, g} V_{y, a, g} V_{z, a, g} M_{t, a, g} N_{x, b, g} M_{y, b, g} M_{z, b, g} V_{y, b, g} V_{z, b, g} M_{t, b, g}\right]^{\top}
$$

The elements in the section force equilibrium matrix $\mathbf{G}$ ensures equilibrium with the section forces in $\mathbf{G}_{0}$ in all degrees of freedom on the two end surfaces. When global section forces are applied through (8) the equilibrium matrix $\mathbf{H}$ and the load vector $\mathbf{R}$ are reduced, hence the degrees of freedom from the end surfaces are removed from $\mathbf{H}$ and $\mathbf{R}$, such that both constraints ( $1 b)$ and (8) can be fulfilled. The reduced matrix and the reduced vector are renamed $\mathbf{H}_{R}$ and $\mathbf{R}_{R}$, respectively.

The complete optimization problem is constructed by adding the three constraints (4), (5), and (8) to the truss optimization problem (1), and by modifying constraint (1b) according to the previous

$$
\begin{gathered}
\min _{\boldsymbol{\beta}, \mathbf{A}} \mathbf{A}^{\top} \mathbf{L} \\
\text { s.t. } \quad \mathbf{H}_{R} \boldsymbol{\beta}=\mathbf{R}_{R} \\
\mathbf{C} \boldsymbol{\beta}-\mathbf{C}_{m} \mathbf{A} \leq \mathbf{0} \\
-\mathbf{I} \boldsymbol{\beta}-\mathbf{P A} \leq \mathbf{q} \\
\mathbf{D A}=\mathbf{A}_{0} \\
\mathbf{S A}=\mathbf{0} \\
\mathbf{G} \boldsymbol{\beta}=\mathbf{G}_{0}
\end{gathered}
$$

$$
\mathbf{K}_{G}\left(\boldsymbol{\beta}_{k}\right)+\mathbf{K}(\mathbf{A}) \succeq 0 \quad \forall k=1, \ldots, N_{k}
$$

This optimization problem, shown in its primal formulation, is solved by its dual formulation, similarly to the technique presented in Baandrup et al. (2020). The derivation of the dual formulation is given in Appendix II.

\section{Results}

Initially, the methods and girder model are validated, followed by an optimization study of the bridge girder. As the basic optimization problem (1) was validated and demonstrated in Poulsen et al. (2020), focus is on the additional constraints (10e), (10f), and $(10 g)$. However, because the constraint on the fixed top plate is evident, and the validity of the symmetry constraints is obvious from the result plots, only the implementation of the global section forces needs to be validated. Subsequently, optimization of the bridge girder model with two individual and simple load cases is demonstrated before the optimization results with all 14 load cases are presented. Finally, two parameter studies with varying top plate thickness and domain height, respectively, are carried out.

For all structures, the meshes are described by the number of nodes in the $x, y$, and $z$ direction by $n_{x}, n_{y}$, and $n_{z}$, respectively, and the connectivity is given by the parameter $r$. If $r=1$ all nodes are connected with elements to their nearest nodes in all directions, if $r=2$ all 
nodes are connected to the nearest as well as the next-to-nearest nodes in all directions, and so on. In all cases the material parameters are given as $E=210 \mathrm{GPa}$ and $f_{y}=335 \mathrm{MPa}$, equivalent to the Osman Gazi Bridge. Results with and without the stability constraints are shown. When stability constraints are included, also the heuristic methods to reduce truss complexity are included.

The code was implemented in Matlab R2016b (MATLAB 2016) and the convex solver was Mosek version 8.1.0.62 (MOSEK 2018).

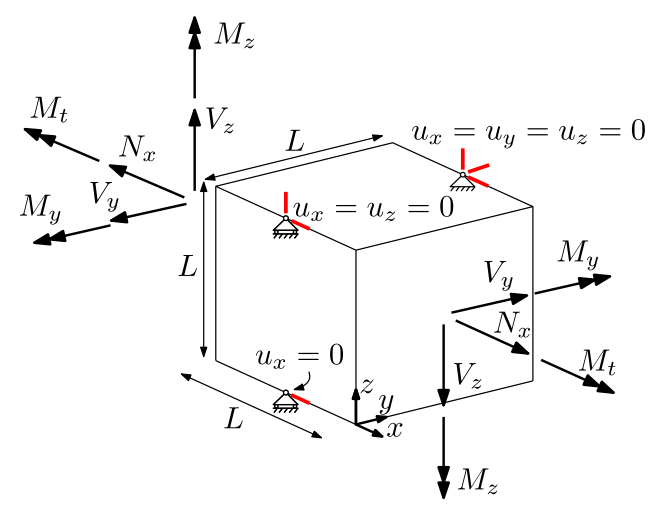

Fig. 9. Domain, boundary conditions, and loads of cube model for validation.

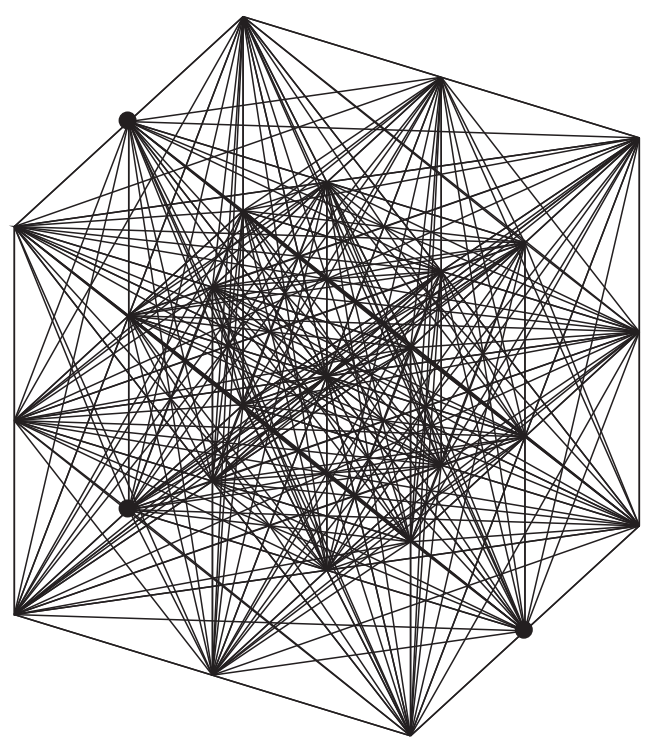

Fig. 10. Initial ground structure of the cube model, $N_{e}=335$.

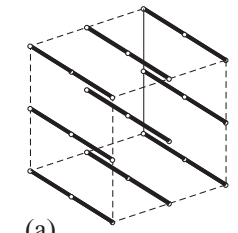

(a)

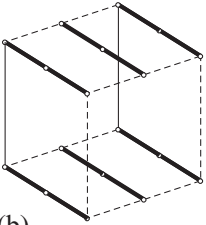

(b)

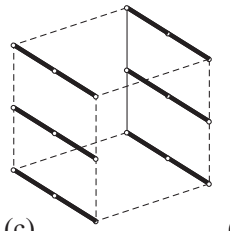

(c)

\section{Validation of Global Section Force Implementation}

The implementation of the global section forces are validated through a study of the six individual section forces applied to a cubical domain. The cube model with dimension $L=5 \mathrm{~m}$, boundary conditions, and loads are shown in Fig. 9. The boundary conditions are applied only to avoid a singular system, because all loads are in equilibrium. The loads are defined as $N_{x}=1 \mathrm{MN}, M_{y}=2.5 \mathrm{MN} \mathrm{m}, M_{z}=$ $2.5 \mathrm{MN} \mathrm{m}, V_{y}=1 \mathrm{MN}, V_{z}=1 \mathrm{MN}$, and $M_{t}=5 \mathrm{MN} \mathrm{m}$. To apply shear, counteracting bending moments $-M_{z}$ and $M_{y}$ are applied together with $V_{y}$ and $V_{z}$, respectively. The mesh parameters are given as $n_{x}=n_{y}=n_{z}=3$ and $r=2$ (all nodes interconnected), generating $N_{e}=335$ elements in the ground structure, shown in Fig. 10.

Initially, the cube model is optimized without the stability constraints, hence problem (10) without $(10 d),(10 e)$, and (10h). The results for the six global section forces are shown in Fig. 11, and it appears that in all cases the structure is in accordance with the loading.

Next, the cube model is optimized with both stability constraints, hence problem (10) without (10e). The results for the six global section forces are shown in Fig. 12. From the six subfigures it appears, again, that the structures are in accordance with the loading. As discussed in Poulsen et al. (2020), the inclusion of global stability constraints introduces many thin members, in addition to the main members, to ensure overall global stability. Furthermore, the inclusion of local stability constraints leads to fewer but larger main members, as seen in all cases when Fig. 12 is compared with Fig. 11. The reason for this is found in the benefit of collecting material in fewer and larger members, being less prone to local instability, as compared with many slender members. Finally, it is emphasized, when including local stability, that the optimization problem becomes nonconvex, hence no global optimum is guaranteed, instead many local optima may exist.

\section{Optimization of the Bridge Girder Model}

For all cases of the bridge girder optimization, the same initial ground structure is applied. The mesh is shown in Fig. 13 and defined by an initial grid of $n_{x}=9, n_{y}=11$, and $n_{z}=3$ nodes with a connectivity $r=2$. The node grid and mesh are adapted to the shape of the domain and consist in total of $N=243$ nodes and $N_{e}=6,665$ elements.

When visualizing results, a threshold is applied to members with zero or negligible cross-sectional areas, for clarity. Two threshold values, relative to the largest cross-sectional area, are applied to identify the main structure $\left(N_{e, \text { Main }} \mid a_{e}>0.1 a_{e, \text { max }}\right)$ and the detailed structure $\left(N_{e, \text { Det. }} \mid a_{e}>0.01 a_{e \text {,max }}\right)$, respectively.

The objective function of volume $V\left[\mathrm{~m}^{3}\right]$, Equation $(10 a)$, is transformed into weight per meter of girder, $W=V \cdot \rho / 25 \mathrm{~m}$, where the density of steel is given as $\rho=7.85 \mathrm{ton} / \mathrm{m}^{3}$. For comparison, the weight (without walkway) of the Osman Gazi Bridge is 11.13 ton $/ \mathrm{m}$, where the top part (top plate and troughs) accounts for $5.25 \mathrm{ton} / \mathrm{m}(47.2 \%)$, and the lower part accounts for

Fig. 11. Solutions of cube model for six individual global section forces, with symmetry, without stability constraints. Boundary of domain indicated by dashed lines: (a) $N_{x}$; (b) $M_{y}$; (c) $M_{z}$; (d) $V_{y}$ and $M_{z}$; (e) $V_{z}$ and $M_{y}$; and (f) $M_{t}$. 

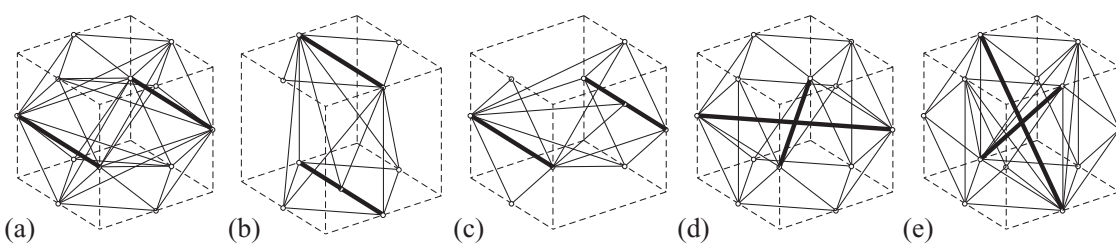

(e)

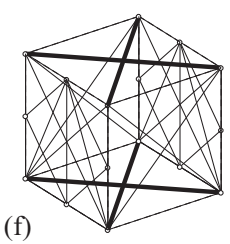

Fig. 12. Solutions of cube model for six individual global section forces, with symmetry, and stability constraints. Boundary of domain indicated by dashed lines: (a) $N_{x}$; (b) $M_{y}$; (c) $M_{z}$; (d) $V_{y}$ and $M_{z}$; (e) $V_{z}$ and $M_{y}$; and (f) $M_{t}$.

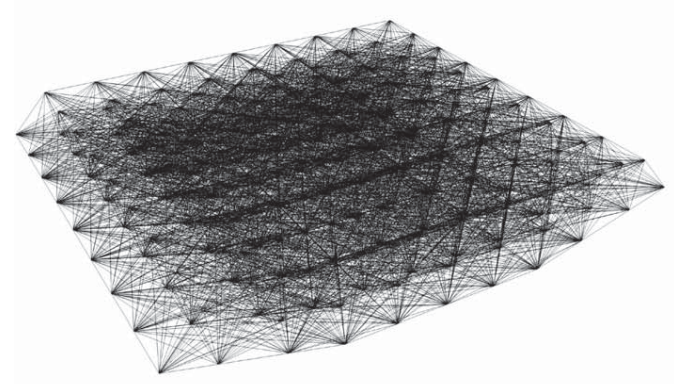

(a)

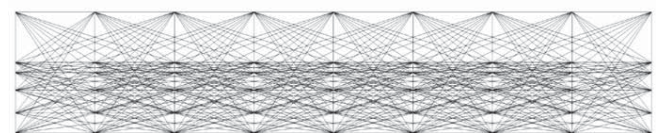

(c)
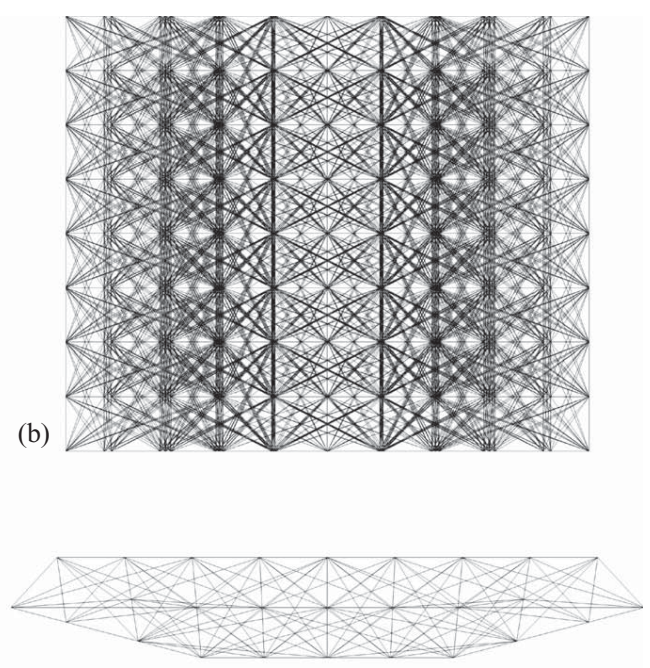

(d)

Fig. 13. Initial ground structure of the bridge girder section, $N_{e}=6,665$ : (a) perspective view; (b) top view; (c) side view; and (d) front view.
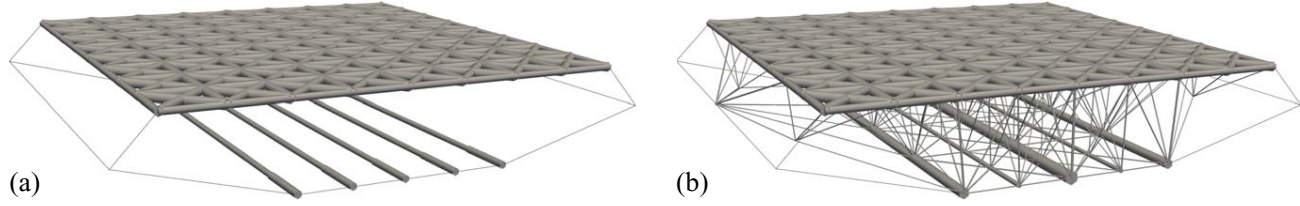

Fig. 14. Bridge girder model optimized for a single load case of pure bending moment $M_{y}=242 \mathrm{MN}$ m applied at both end surfaces. Perspective view with truss top plate. Boundary of domain indicated by thin lines: (a) without stability constraints; and (b) with stability constraints.

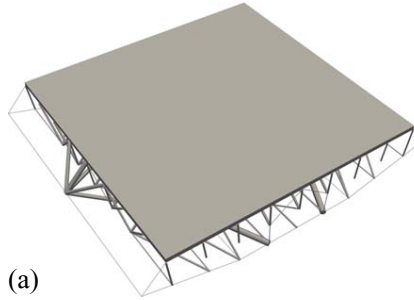

(b)

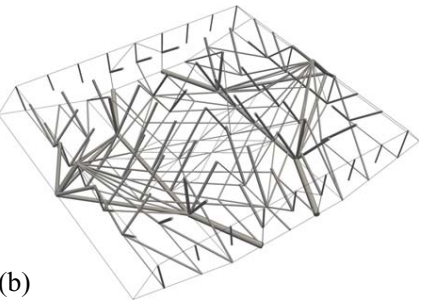

(c)

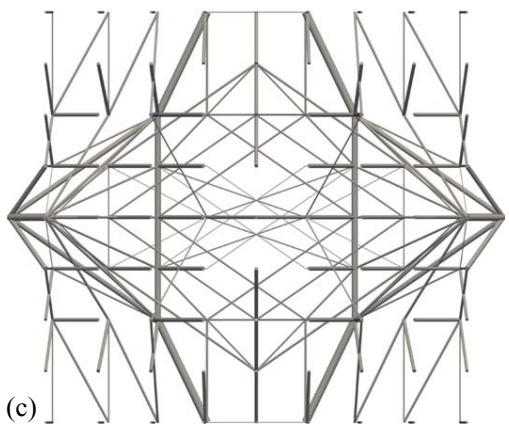

Fig. 15. Bridge girder result optimized for a single load case of distributed load and hanger forces (LC 13), $W=4.27$ ton/m. Detailed structure, $N_{e, \text { Det. }}=382$. Boundary of domain indicated by thin lines on perspective views: (a) perspective view, with top plate; (b) perspective view, without top plate; and (c) top view, without top plate.

$5.88 \mathrm{ton} / \mathrm{m}$. The assumed fixed top plate of thickness $t_{t p}=20 \mathrm{~mm}$ accounts for $4.03 \mathrm{ton} / \mathrm{m}$ in the truss girder designs.

\section{Optimization with a Single Load Case}

First, the bridge girder model is subject to a pure bending moment $M_{y}=242 \mathrm{MN} \mathrm{m}$ (equivalent to the largest bending moment in the
12 global load cases) at both end surfaces, similarly to the cube model in Figs. 11(b) and 12(b). The optimization problem is solved with and without the stability constraints $(10 d)$ and (10h). The results are shown in Fig. 14. It is shown in Fig. 14(a) how the structure is optimized to carry the bending moment, with material distributed in top and bottom to maximize the second moment of 

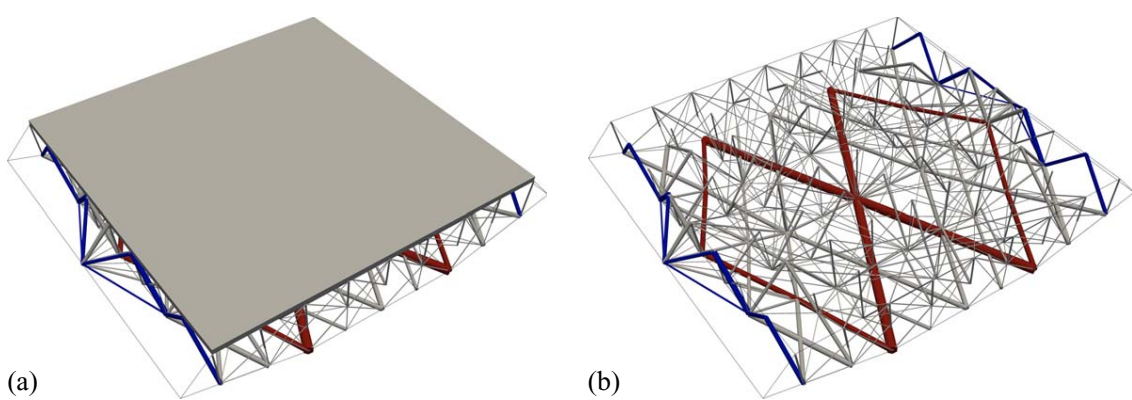

Fig. 16. Bridge girder result optimized for 14 load cases (LC 1-14), $W=6.09$ ton $/ \mathrm{m}$. Perspective view of detailed structure, $N_{e, \text { Det. }}=472$. Boundary of domain indicated by thin lines: (a) with top plate; and (b) without top plate.

area. In Fig. 14(b) the effect of the global stability constraint is shown in the many additional members. Furthermore, the effect of the local stability constraint is shown in the lower part (in compression), where the material is mainly concentrated in three members, as opposed to the five members in Fig. 14(a). Despite the effects of the stability constraints, the structure is clearly still optimized to carry the bending moment.

Second, the bridge girder model is optimized for a single local load case with distributed load over the entire top surface and equivalent hanger forces (LC 13 in Table 3 in Appendix I). The complete optimization problem, (10), including stability and symmetry constraints, and the fixed top plate, is solved. The optimized girder, visualized with the detailed structure of $N_{e, \text { Det. }}=382$ elements $\left(N_{e, \text { Main }}=286\right)$, is shown in Fig. 15 . From the figure, it is shown how the material is distributed more densely close to the hanger anchorage, to which all distributed surface load is transferred, and hence the forces are the largest. In contrast, the amount of material decreases towards the center of the girder and towards the center line between hangers. Thus, the structure is clearly optimized to carry the distributed load to the hangers. The weight is found to be $4.27 \mathrm{ton} / \mathrm{m}$, where the top plate of $4.03 \mathrm{ton} / \mathrm{m}$ accounts for $94.4 \%$ and the lower part thus accounts for 0.24 ton $/ \mathrm{m}$. The large ratio between the weight of the upper and lower parts indicates that the top plate is oversized for this less severe load case.

\section{Optimization with 14 Load Cases}

Next, the bridge girder model is optimized for all 14 load cases (LC 1-14 in Table 3 in Appendix I). A single section of the optimized girder, visualized with the detailed structure of $N_{e, \text { Det. }}=472$ elements, is shown in Fig. 16. Three sections of the continuous girder are shown together in Fig. 17, to emphasize the design. For clarity, only the main structure with $N_{e \text {, Main }}=344$ elements per section is shown. In both Figs. 16 and 17 notable members are highlighted to enhance the design concept.In Figs. 16 and 17 a significantly different design is shown, compared with that in Fig. 15. The effects from the global section forces are clearly visible, in particular the large torsion and bending moments are governing the design. Hence, a torsion grid along the circumference of the domain is shown, as well as large longitudinal members in the lower part of the domain. Furthermore, the optimized design is very different from the conventional design (Fig. 2), not only because truss structures are studied, but also due to the overall structural concept. Loads are carried more directly to the hangers, and transferred to the main bottom grid, to be carried by efficient tension members. Thus, the material is utilized more efficiently, compared with the conventional design where loads are carried to the hangers via perpendicular plate structures. In particular, two important design principles are identified. The first principle which is highlighted in red (dark gray in grayscale), includes the largest bottom members spanning across two sections, from the hanger in
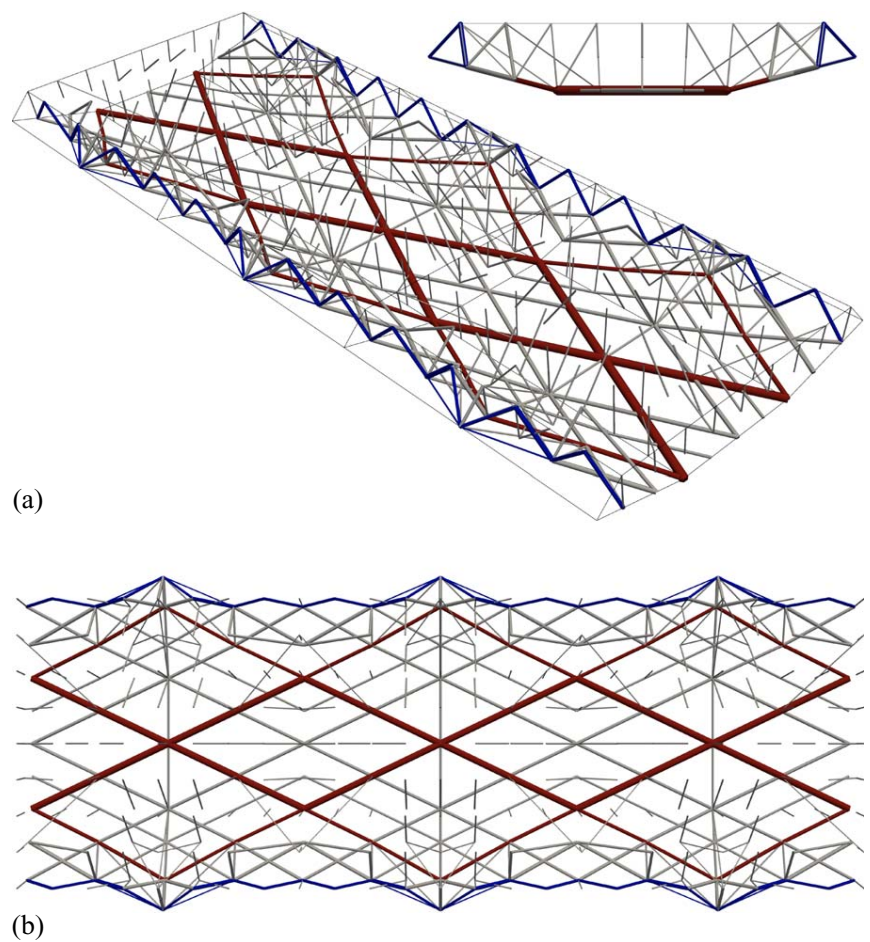

(b)

Fig. 17. Bridge girder result optimized for 14 load cases (LC 1-14), three spans, $W=6.09 \mathrm{ton} / \mathrm{m}$. Main structure without top plate, $N_{e, \text { Main }}=344$ per section: (a) perspective and section view, with boundary of domain indicated by thin lines; and (b) top view.

Table 1. Study of varying top plate thickness $t_{t p}$ for the Osman Gazi bridge and four truss girder cases. Weight savings are given relative to the total weight of the Osman Gazi Bridge

\begin{tabular}{|c|c|c|c|c|c|c|}
\hline Case & $\begin{array}{c}t_{t p} \\
(\mathrm{~mm})\end{array}$ & $\begin{array}{c}\text { Total } \\
\text { weight } \\
\text { (ton } / \mathrm{m})\end{array}$ & $\begin{array}{c}\text { Weight } \\
\text { saving } \\
(-)\end{array}$ & $\begin{array}{l}\text { Weight } \\
\text { of top } \\
\text { plate } \\
\text { (ton } / \mathrm{m} \text { ) }\end{array}$ & $\begin{array}{c}\text { Weight of } \\
\text { lower } \\
\text { part } \\
\text { (ton } / \mathrm{m})\end{array}$ & $\begin{array}{l}\text { Ratio } \\
\text { between top } \\
\text { plate and } \\
\text { total weight } \\
\quad(-)\end{array}$ \\
\hline Osman & $26^{\mathrm{a}}$ & 11.13 & - & 5.25 & 5.88 & $47.2 \%$ \\
\hline $\begin{array}{l}\text { Gazi } \\
1\end{array}$ & 10 & 4.09 & $63.2 \%$ & 2.02 & 2.07 & $49.4 \%$ \\
\hline 2 & 15 & 5.11 & $54.1 \%$ & 3.03 & 2.08 & $59.3 \%$ \\
\hline 3 & 20 & 6.09 & $45.3 \%$ & 4.03 & 2.06 & $66.2 \%$ \\
\hline 4 & 25 & 7.09 & $35.3 \%$ & 5.04 & 2.05 & $71.1 \%$ \\
\hline
\end{tabular}

${ }^{a}$ Equivalent plate thickness of the orthotropic top deck (top plate and troughs). 

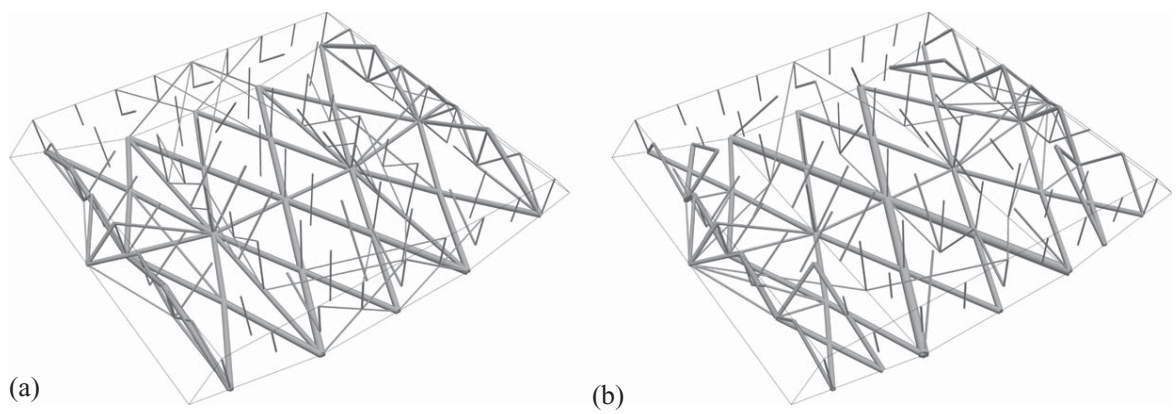

Fig. 18. Bridge girder results (14 load cases) for Case 1 and 2 in Table 1, perspective view of main structure without top plate. Boundary of domain indicated by thin lines: (a) top plate thickness $t_{t p}=10 \mathrm{~mm}, W=4.09 \mathrm{ton} / \mathrm{m}, N_{e ; \text { Main }}=342$; and (b) top plate thickness $t_{t p}=15 \mathrm{~mm}, W=5.11$ ton $/ \mathrm{m}$, $N_{e ; \text { Main }}=332$.

one side, through the neighboring section, to the hanger in the opposite side. Thus, the interaction between the sections reaches further than to the nearest neighboring sections in order to support bending and torsional moments efficiently. This principle emerges from the optimization, although the mesh (Fig. 13) allows for a span between hangers crossing a single section only. The second principle which is highlighted in blue (black in grayscale), is characterized by the curved narrowing of the girder between hangers, without exploiting the entire domain width.

The weight of the girder is found as $6.09 \mathrm{ton} / \mathrm{m}$, where the weight of the top plate, $4.03 \mathrm{ton} / \mathrm{m}$, accounts for $66.2 \%$ and the weight of the lower part is $2.06 \mathrm{ton} / \mathrm{m}$. The total weight is equivalent to $54.7 \%$ of the Osman Gazi Bridge. This significant weight reduction indicates the large potential in alternative truss-based design concepts. In all weight measures, the contribution from connections (weldings and bolts) has been neglected. Furthermore, construction costs have not been considered. However, concerns about construction cost are subordinate to self-weight issues, which are crucial to the possible achievement of very-long suspension bridges (main span beyond $2 \mathrm{~km}$ ).

The ratio between the weight of the top plate and the total weight $(66.2 \%)$ is higher compared with the Osman Gazi Bridge (47.2\%), indicating a conservative choice of the equivalent top plate thickness of $20 \mathrm{~mm}$. Therefore, the effect of reducing the top plate thickness is studied in the following.

\section{Top Plate Thickness}

As the top plate thickness is fixed during optimization, a parameter study of varying thickness, $t_{t p}$, is carried out. The complete girder model with all 14 load cases is studied with fixed thicknesses varying from 10 to $25 \mathrm{~mm}$, with $5 \mathrm{~mm}$ intervals. The results of the study are summarized in Table 1, where the Osman Gazi Bridge has been included for reference.

In Case 3, the ratio between the weight of the top plate and the total weight is higher compared with the ratio of the conventionally designed Osman Gazi Bridge, indicating a further potential saving by reducing the top plate thickness. In Case 1 , with $t_{t p}=10 \mathrm{~mm}$, the ratio is reduced to $49.4 \%$ which is close to the conventional design. With $t_{t p}=10 \mathrm{~mm}$ the total weight of $4.09 \mathrm{ton} / \mathrm{m}$ is equivalent to $36.7 \%$ of the Osman Gazi Bridge. However, an equivalent top plate of $10 \mathrm{~mm}$ thickness is most likely not capable of spanning $3 \mathrm{~m}$ while carrying the traffic. With a thicker equivalent top plate of $t_{t p}=15 \mathrm{~mm}$, the total weight of $5.11 \mathrm{ton} / \mathrm{m}$ is equivalent to $45.9 \%$ of the Osman Gazis Bridge.

The truss girder designs for Case 1 and 2 are shown in Fig. 18, visualizing the main structure of a single section. The equivalent visualization of Case 3 is shown in Fig. 17(a), while the visualization of Case 4 has been omitted.In the designs of both Case 1 and 2, the
Table 2. Study of varying domain height $H$ for four cases

\begin{tabular}{llllc}
\hline Case & 1 & \multicolumn{1}{c}{2} & \multicolumn{1}{c}{3} & 4 \\
\hline Height $H(\mathrm{~m})$ & 4.75 & 6.0 & 8.0 & 10.0 \\
Weight $W(\mathrm{ton} / \mathrm{m})$ & 6.09 & 5.77 & 5.50 & 5.42 \\
\hline
\end{tabular}

bottom grid is more uniform, compared with Fig. 17(a) where the grid consists of distinct primary and secondary members. This effect can be seen as a result of the reduced top plate thickness, hence more material is concentrated in the bottom of the domain. Similarly, in Case 1, pronounced longitudinal members are formed in the bottom to counteract the decreased longitudinal strength in the top part, owing to the thinner top plate. Despite the changes to the design, the main principles are similar to Case 3.

\section{Domain Height}

Finally, a study of the effect on the girder weight from varying the domain height $H$ is carried out. The study is carried out by increasing the height $H$ (Fig. 3) while the mesh given in Fig. 13 scales. A summary of the study of domain heights from 4.75 to $10 \mathrm{~m}$ is listed in Table 2. From the table it is demonstrated that by increasing the domain height, the weight decreases. This effect is expected, owing to the benefits from increased height on the torsion and bending moment capacities. However, in general, the weight reduction is modest. Further, the effect decreases with increasing height, thus the change from Case 3 to 4 is significantly smaller than from Case 1 to 2 .

\section{Conclusions}

Truss topology optimization, including stress constraints, as well as global and local stability constraints, was applied in the study of new conceptual designs for girders in cable-supported bridges. In addition to the basic optimization problem, novel constraints were added to account for an assumed top plate, symmetry, and the application of global section forces, in order to establish the necessary conditions to model a bridge girder section. The girder model was subject to local and global loads, and optimized with the goal of minimizing the total weight. The implementation of the imposed global section forces was validated by simple examples, both without and with stability constraints. Subsequently, the bridge girder model was studied under individual and simple load cases. Finally, optimization including all considered load cases was carried out in order to identify potential new design concepts and weight savings. Owing to the truss structure approach, designs showing new and efficient load carrying principles, which are significantly different from the conventional design, emerged from the optimization. Here, the main 
structure consisted of a torsion grid along the circumference of the domain, as well as large members in the bottom to carry bending moments. Furthermore, load paths were oriented more directly towards the hanger attachments, and running through the bottom part to benefit from tension members. The total girder weight of 6.09 ton $/ \mathrm{m}$ was equivalent to only $54.7 \%$ of the conventionally designed girder of the Osman Gazi Bridge. Hence, the significant weight reduction and new design principles indicate the potential of these alternative design concepts. Moreover, the two parameter studies on the top plate thickness and the domain height indicate possible further weight reduction. The most significant effect was found in reducing the top plate thickness, whereby the ratio between the weight of the top plate and the total weight of the girder approaches the ratio of the conventional design.

In general, the new design principles and possible weight reductions indicate the potential of alternative truss-based design concepts. Although the construction cost has been neglected, the potentials are highly relevant to very-long suspension bridges with spans beyond $2 \mathrm{~km}$, for which low self-weight is crucial.

\section{Appendix I. Table of Load Cases}

The 12 global load cases (LC 1-12) and two local load cases (LC 13 and 14) are listed in Table 3. Load cases 1-12 are identified from a global beam model of the Osman Gazi Bridge. Each of these is identified based on the maximum and minimum section forces in the girder on end surface $a$, hence LC1 is derived from the maximum $N_{x}$, LC2 from minimum $N_{x}$, LC3 from maximum $M_{y}$, and so on. As demonstrated by the table, load cases 6 and 8 are identical, hence the minimum bending moment $M_{z}$ and minimum shear force $V_{y}$ occur in the same load case and at the same girder location in the global beam model. Consequently, one of these load cases can be neglected in the optimization to reduce the problem size.

\section{Appendix II. Dual Formulation of the Complete Optimization Problem}

Similar to the technique in Baandrup et al. (2020), the dual formulation of problem (10) is derived in the following. To handle the semidefinite constraint $(10 h)$ in the formulation of the Lagrangian of the problem, a semidefinite dual variable $\mathbf{Y}_{k} \forall k=1, \ldots, N_{k}$ is introduced. To derive the Lagrangian function a self-adjoint operator on $\mathbf{Y}_{k}$ is defined as $\sum_{k=1}^{N_{k}}\left\langle\mathbf{K}_{S, k}\left(\boldsymbol{\beta}_{k}, \mathbf{A}\right), \mathbf{Y}_{k}\right\rangle=$ $\left[\begin{array}{ll}\boldsymbol{\beta}^{\top} & \mathbf{A}^{\top}\end{array}\right] \sum_{k=1}^{N_{k}} \mathbf{K}_{S, k}^{*}\left(\mathbf{Y}_{k}\right)$. The reader is referred to Baandrup et al. (2020) for details on the adjoint operator. The Lagrangian of problem (10) is given as

$$
\begin{aligned}
\mathcal{L}\left(\boldsymbol{\beta}, \mathbf{A}, \mathbf{y}, \mathbf{z}, \mathbf{t}, \mathbf{u}, \mathbf{v}, \mathbf{w}, \mathbf{Y}_{k}\right)= & {\left[\begin{array}{ll}
\mathbf{0} & \mathbf{L}^{\top}
\end{array}\right]\left[\begin{array}{l}
\boldsymbol{\beta} \\
\mathbf{A}
\end{array}\right]-\mathbf{y}^{\top}\left(\left[\begin{array}{ll}
{\left[\mathbf{H}_{R}\right.} & \mathbf{0}
\end{array}\right]\left[\begin{array}{l}
\boldsymbol{\beta} \\
\mathbf{A}
\end{array}\right]-\mathbf{R}_{R}\right) } \\
& +\mathbf{z}^{\top}\left(\left[\begin{array}{ll}
\mathbf{C} & -\mathbf{C}_{m}
\end{array}\right]\left[\begin{array}{l}
\boldsymbol{\beta} \\
\mathbf{A}
\end{array}\right]\right)+\mathbf{t}^{\top}\left(\left[\begin{array}{ll}
-\mathbf{I} & -\mathbf{P}
\end{array}\right]\left[\begin{array}{l}
\boldsymbol{\beta} \\
\mathbf{A}
\end{array}\right]-\mathbf{q}\right)-\mathbf{u}^{\top}\left(\left[\begin{array}{ll}
\mathbf{0} & \mathbf{D}
\end{array}\right]\left[\begin{array}{l}
\boldsymbol{\beta} \\
\mathbf{A}
\end{array}\right]-\mathbf{A}_{0}\right) \\
& -\mathbf{v}^{\top}\left(\left[\begin{array}{ll}
{[\mathbf{0}} & \mathbf{S}
\end{array}\right]\left[\begin{array}{l}
\boldsymbol{\beta} \\
\mathbf{A}
\end{array}\right]\right)-\mathbf{w}^{\top}\left(\left[\begin{array}{ll}
\mathbf{G} & \mathbf{0}
\end{array}\right]\left[\begin{array}{l}
\boldsymbol{\beta} \\
\mathbf{A}
\end{array}\right]-\mathbf{G}_{0}\right)-\sum_{k=1}^{N_{k}}\left\langle\mathbf{K}_{S, k}\left(\boldsymbol{\beta}_{k}, \mathbf{A}\right), \mathbf{Y}_{k}\right\rangle \\
= & {\left[\begin{array}{ll}
\boldsymbol{\beta}^{\top} & \mathbf{L}^{\top}
\end{array}\right]\left(\left[\begin{array}{l}
\mathbf{0} \\
\mathbf{L}
\end{array}\right]-\left[\begin{array}{c}
\mathbf{H}_{R}^{\top} \\
\mathbf{0}
\end{array}\right] \mathbf{y}+\left[\begin{array}{c}
\mathbf{C}^{\top} \\
-\mathbf{C}_{m}^{\top}
\end{array}\right] \mathbf{z}+\left[\begin{array}{c}
-\mathbf{I} \\
-\mathbf{P}^{\top}
\end{array}\right] \mathbf{t}-\left[\begin{array}{c}
\mathbf{0} \\
\mathbf{D}^{\top}
\end{array}\right] \mathbf{u}-\left[\begin{array}{c}
\mathbf{0} \\
\mathbf{S}^{\top}
\end{array}\right] \mathbf{v}\right.} \\
& \left.-\left[\begin{array}{c}
\mathbf{G}^{\top} \\
\mathbf{0}
\end{array}\right] \mathbf{w}-\sum_{k=1}^{N_{k}} \mathbf{K}_{S, k}^{*}\left(\mathbf{Y}_{k}\right)\right)+\mathbf{R}_{R}^{\top} \mathbf{y}-\mathbf{q}^{\top} \mathbf{t}+\mathbf{A}_{0}^{\top} \mathbf{u}+\mathbf{G}_{0}^{\top} \mathbf{w}
\end{aligned}
$$

\begin{tabular}{|c|c|c|c|c|c|c|c|c|c|c|c|c|c|c|}
\hline $\mathrm{LC}$ & $\begin{array}{c}N_{x, a} \\
(\mathrm{MN})\end{array}$ & $\begin{array}{c}M_{y, a} \\
(\mathrm{MN} \mathrm{m})\end{array}$ & $\begin{array}{c}M_{z, a} \\
(\mathrm{MN} \mathrm{m})\end{array}$ & $\begin{array}{c}V_{y, a} \\
(\mathrm{MN})\end{array}$ & $\begin{array}{c}V_{z, a} \\
(\mathrm{MN})\end{array}$ & $\begin{array}{c}M_{t, a} \\
(\mathrm{MNm})\end{array}$ & $\begin{array}{l}N_{x, b} \\
(\mathrm{MN})\end{array}$ & $\begin{array}{c}M_{y, b} \\
(\mathrm{MN} \text { m) }\end{array}$ & $\begin{array}{c}M_{z, b} \\
(\mathrm{MN} \mathrm{m})\end{array}$ & $\begin{array}{c}V_{y, b} \\
(\mathrm{MN})\end{array}$ & $\begin{array}{c}V_{z, b} \\
(\mathrm{MN})\end{array}$ & $\begin{array}{c}M_{t, b} \\
(\mathrm{MN} \mathrm{m})\end{array}$ & $\begin{array}{c}\text { Dist. } p \\
\left(\mathrm{kN} / \mathrm{m}^{2}\right)\end{array}$ & $\begin{array}{l}\text { Hanger } \\
P(\mathrm{MN})\end{array}$ \\
\hline 1 & 9.29 & -10.46 & 18.93 & 0.16 & 1.43 & -20.12 & -9.29 & -24.77 & -14.91 & -0.16 & -1.39 & 20.12 & -7.66 & 2.45 \\
\hline 2 & -16.58 & -75.21 & 47.72 & -0.06 & -1.18 & 47.79 & 16.58 & 84.39 & -49.34 & 0.06 & -0.45 & -47.79 & -8.83 & 3.65 \\
\hline 3 & 2.07 & 236.57 & 35.42 & 0.24 & 1.66 & 26.45 & -2.07 & -242.34 & -29.53 & -0.24 & 1.20 & -26.45 & -15.60 & 3.58 \\
\hline 4 & -4.08 & -155.36 & -6.27 & 0.01 & 0.09 & 34.30 & 4.08 & 119.82 & 6.65 & -0.015 & -2.75 & -34.30 & -8.59 & 4.09 \\
\hline 5 & -0.08 & -5.40 & 704.06 & -4.56 & 0.07 & 9.20 & 0.08 & 18.82 & -818.17 & 4.56 & 1.15 & -9.20 & -8.77 & 2.21 \\
\hline 6 & 1.29 & -30.53 & -779.78 & -5.45 & 1.64 & -24.37 & -1.29 & 8.53 & 643.56 & 5.45 & -0.12 & 24.37 & -9.90 & 2.42 \\
\hline 7 & -0.11 & -24.28 & 712.49 & 5.33 & 1.25 & 8.37 & 0.11 & 8.57 & -579.27 & -5.33 & 0.00 & -8.37 & -8.77 & 2.19 \\
\hline 8 & 1.29 & -30.53 & -779.78 & -5.45 & 1.64 & -24.37 & -1.29 & 8.5 & 643.56 & 5.45 & -0.12 & 24.37 & -9.90 & 2.42 \\
\hline 9 & 6.11 & -142.86 & -16.49 & -0.16 & 1.54 & 53.50 & -6.11 & 75.78 & 12.49 & 0.16 & -3.83 & -53.50 & -6.46 & 3.22 \\
\hline 10 & -13.32 & 42.33 & -23.89 & 0.04 & -5.22 & -53.72 & 13.32 & 46.88 & 24.89 & -0.04 & 1.92 & 53.72 & -2.76 & 2.54 \\
\hline 11 & -0.04 & 35.64 & -230.91 & -0.18 & 1.35 & 184.41 & 0.04 & -39.93 & 226.49 & 0.18 & 1.01 & -184.41 & -14.53 & 3.49 \\
\hline 12 & 2.04 & 41.39 & 239.93 & 0.17 & 1.33 & -179.25 & -2.04 & -45.63 & -235.75 & -0.17 & 0.99 & 179.25 & -14.00 & 3.34 \\
\hline 13 & - & 20.10 & - & - & - & - & - & -20.10 & - & - & - & - & -5.00 & 1.61 \\
\hline $14^{\mathrm{a}}$ & - & 10.0 & - & - & - & - & - & -10.0 & - & - & - & - & -5.00 & 0.80 \\
\hline
\end{tabular}

Table 3. Bridge girder load cases (LC): LC 1-12, global; LC 13 and 14, local

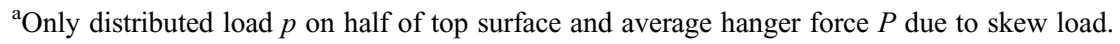


By differentiating (11b) with respect to the primal variables $(\boldsymbol{\beta}, \mathbf{A})$, the dual of (10) can be formed as

$$
\begin{gathered}
\min _{\mathbf{y}, \mathbf{z}, \mathbf{t}, \mathbf{u}, \mathbf{v}, \mathbf{w}, \mathbf{Y}_{k}}-\mathbf{R}_{R}^{\top} \mathbf{y}+\mathbf{q}^{\top} \mathbf{t}-\mathbf{A}_{0}^{\top} \mathbf{u}-\mathbf{G}_{0}^{\top} \mathbf{w} \\
\text { s.t. }\left[\begin{array}{c}
\mathbf{H}_{R}^{\top} \\
\mathbf{0}
\end{array}\right] \mathbf{y}-\left[\begin{array}{c}
\mathbf{C}^{\top} \\
-\mathbf{C}_{m}^{\top}
\end{array}\right] \mathbf{z}+\left[\begin{array}{c}
\mathbf{I} \\
\mathbf{P}^{\top}
\end{array}\right] \mathbf{t}+\left[\begin{array}{c}
\mathbf{0} \\
\mathbf{D}^{\top}
\end{array}\right] \mathbf{u}+\left[\begin{array}{c}
\mathbf{0} \\
\mathbf{S}^{\top}
\end{array}\right] \mathbf{v} \\
+\left[\begin{array}{c}
\mathbf{G}^{\top} \\
\mathbf{0}
\end{array}\right] \mathbf{w}+\sum_{k=1}^{N_{k}} \mathbf{K}_{S, k}^{*}\left(\mathbf{Y}_{k}\right)=\left[\begin{array}{c}
\mathbf{0} \\
\mathbf{L}
\end{array}\right] \\
\mathbf{z} \geq \mathbf{0} \\
\mathbf{t} \geq \mathbf{0} \\
\quad \forall k=1, \ldots, N_{k}
\end{gathered}
$$

with the dual variables $\mathbf{y}, \mathbf{z}, \mathbf{t}, \mathbf{u}, \mathbf{v}, \mathbf{w}$, and $\mathbf{Y}_{k}$.

\section{Data Availability Statement}

Some or all data, models, or code generated or used during the study are available from the corresponding author by request. This includes the Matlab input files to the demonstrated problems.

\section{Acknowledgments}

The presented work is part of an industrial $\mathrm{PhD}$ project with the title "Innovative design of steel bridge girders in cable-supported bridges" and is carried out in cooperation with COWI A/S, DTU Civil Engineering, and DTU Mechanical Engineering. The project is supported financially by the COWI Foundation grant C-131.02 and Innovation Fund Denmark grant 5189-00112B.

\section{References}

Aygül, M., M. Al-Emrani, and S. Urushadze. 2012. "Modelling and fatigue life assessment of orthotropic bridge deck details using FEM." Int. J. Fatigue 40: 129-142. https://doi.org/10.1016/j.ijfatigue .2011.12.015.

Baandrup, M., J. F. Olesen, and P. N. Poulsen. 2020. "Large-scale truss optimization including global and local stability." Struct. Multidiscip. Optim. (in review).

Baandrup, M., P. N. Poulsen, J. F. Olesen, and H. Polk. 2019. "Parametric optimization of orthotropic girders in a cable-supported bridge." J. Bridge Eng. 24 (12): 04019118. https://doi.org/10.1061/(ASCE)BE .1943-5592.0001499.

Backer, H. D., A. Outtier, and P. Van Bogaert. 2006. "Analytical model for the stiffener-to-deck plate detail in orthotropic bridges." In Vol. 2 of Proc., 10th East Asia-Pacific Conf. on Structural Engineering and Construction, 47-52. Pathum Thani, Thailand: Asian Institute of Technology.

Battista, R. C., E. F. Santos, R. Vasconcelos, and M. S. Pfeil. 2010. "A visco-elastic sandwich solution for orthotropic decks of steel bridges." In Proc., SDSS'Rio 2010 Stability and Ductility of Steel
Structures, 149-156. Rio de Janeiro, Brazil: COPPE - Federal University of Rio de Janeiro.

CEN (European Committee for Standardization). 2002. Eurocode 1: Actions on structures - Part 1. Rep. No. EN 1991-1-X:2002. Brussels, Belgium: CEN.

CEN (European Committee for Standardization). 2003. Eurocode 1: Actions on structures - Part 2: Traffic on bridges. Rep. No. EN1991-2:2003. Brussels, Belgium: CEN.

Chu, S., L. Gao, M. Xiao, and H. Li. 2018. "Design of sandwich panels with truss cores using explicit topology optimization." Compos. Struct. 210: 892-905. https://doi.org/10.1016/j.compstruct.2018.12 .010 .

Connor, R. 2004. "Influence of cutout geometry on stresses at welded rib-to-diaphragm connections in steel orthotropic bridge decks." Transp. Res. Rec. 1892 (1): 78-87. https://doi.org/10.3141/1892-09.

Corte, W. D. 2011. "A review of alternatives for orthotropic bridge deck panels." Bridge Struct. 7 (2-3): 95-102. https://doi.org/10.3233/BRS -2011-024.

De Corte, W. 2009. "Parametric study of floorbeam cutouts for orthotropic bridge decks to determine shape factors." Bridge Struct. 5 (2-3): 75-85. https://doi.org/10.1080/15732480903142518.

Diana, G., Y. Yamasaki, A. Larsen, D. Rocchi, S. Giappino, T. Argentini, A. Pagani, M. Villani, C. Somaschini, and M. Portentoso. 2013. "Construction stages of the long span suspension Izmit Bay Bridge: Wind tunnel test assessment." J. Wind Eng. Ind. Aerodyn. 123: 300310. https://doi.org/10.1016/j.jweia.2013.09.006.

Fettahoglu, A. 2016. "Optimizing rib width to height and rib spacing to deck plate thickness ratios in orthotropic decks." Cogent Eng. 3 (1): 1154703. https://doi.org/10.1080/23311916.2016.1154703.

Fisher, J. W., and R. J. Dexter. 1997. "Fatigue cracking of orthotropic steel decks." In Vol. 76 of Proc., IABSE Workshop, IABSE Reports, Zurich, Lausanne, 203-212. Lausanne, Switzerland: Institute for Steel Structures (ICOM), Swiss Federal Institute of Technology.

Gimsing, N. J., and C. T. Georgakis. 2012. Cable supported bridges: Concept and design. Hoboken, NJ: John Wiley \& Sons.

Kozy, B. M., and R. Connor. 2010. "Fatigue design of orthotropic steel bridges." In Proc., Structures Congress 2010, edited by Sivaji Senapathi, Kevin Casey, and Marc Hoit, 541-553. Reston, VA: ASCE.

Oh, C. K., and D. Bae. 2013. "Fatigue test of an advanced orthotropic steel deck system using high performance steel for bridges." Int. J. Steel Struct. 13 (1): 93-101. https://doi.org/10.1007/s13296 $-013-1009-6$

Oh, C. K., K. J. Hong, D. Bae, H. Do, and T. Han. 2011. "Analytical and experimental studies on optimal details of orthotropic steel decks for long span bridges." Int. J. Steel Struct. 11 (2): 227-234. https://doi .org/10.1007/s13296-011-2010-6.

Poulsen, P. N., J. F. Olesen, and M. Baandrup. 2020. "Truss optimization applying finite element limit analysis including global and local stability." Struct. Multidiscip. Optim. 62 (1): 41-54. https://doi.org/10.1007 /s00158-019-02468-4.

Song, Y. S., and Y. L. Ding. 2014. "Influence of local geometric parameters on fatigue performance of orthotropic steel deck." J. Cent. South Univ. 21 (5): 2091-2099. https://doi.org/10.1007/s11771-014 -2158-2.

Wolchuk, R. 1999. "Steel orthotropic decks: Developments in the 1990s." Transp. Res. Rec. 1688 (1): 30-37. https://doi.org/10.3141 /1688-04.

Wolchuk, R., and F. R. Harris. 1959. "Orthotropic plate design of steel bridges." Civil Eng. 29 (2): 38-43.

Zhang, Q.-H. 2017. "Review on fatigue problems of orthotropic steel bridge deck." China J. Highway Transp. 30 (3): 14-39. 